\title{
The Role of Zinc in Renal Pathological Changes in Diabetic Status
}

\section{Julie Fernando and Shaobo Zhou*}

Department of Life Science, Institute of Biological and Environmental Science and Technology (iBEST), Faculty of Creative Arts, Technologies and Science, University of Bedfordshire, Park Square, Luton, LU1 3JU, United Kingdom

\begin{abstract}
Diabetes mellitus (DM) was the $8^{\text {th }}$ leading cause of death in 2011, resulting in 1.4 million deaths worldwide. One of the complications of DM is chronic kidney disease, which accounts for nearly $44 \%$ of all new cases of kidney failure in the US in 2011. Zinc (Zn), an essential trace element, plays an important role in regulating carbohydrate metabolism. Several studies have shown the beneficial effects of $Z n$ on renal pathological changes in Type 1 and Type 2 diabetic subjects, by reducing levels of oxidative stress, glomerular damage, and urinary albumin excretion after $\mathrm{Zn}$ supplementation. In contrast, other studies have shown little effects of $\mathrm{Zn}$ supplementation on renal damage. This paper reviewed recent research developments and found promising results of $Z n$ in reducing, and in some cases, completely preventing renal damage. Nevertheless, the use of $\mathrm{Zn}$ as a potential treatment and especially its long-term impact against renal pathological symptoms in DM patients needs to be further studied.
\end{abstract}

Keywords: Zinc; Diabetes mellitus; Oxidative stress; Chronic hyperglycaemia

\section{Introduction}

Currently, there are 382 million people with diabetes mellitus (DM). Almost 600 million people worldwide will suffer from this condition by $2035[1]$.

Hyperglycaemia, the main underlying symptom of DM, is caused by either a defect in insulin secretion and/or insulin action. Chronic hyperglycaemia and its defects in other related metabolic regulation may be associated with secondary damage in organ systems including the kidneys, eyes, nerves, and blood vessels [2].

There are two main types of diabetes, type 1 and 2 diabetes (T1D and T2D). Renal failure is second to myocardial infarction as a cause of death from DM. Three lesions are typically encountered in DM patients with renal disease, including glomerular lesions, renal vascular lesions, and necrotizing papillitis [3]. The most important glomerular lesions are capillary basement membrane thickening. Excessive glomerulosclerosis can produce adequate levels of ischemia to the kidneys that can develop into end-stage renal disease, requiring dialysis or renal transplantation [3].

Increased DM prevalence rates, predominantly in developing countries, follow the trend of lifestyle changes and certain diets. One particular area in research is zinc ( $\mathrm{Zn})$. The sufficient availability of this transition metal has shown to be essential for biological processes [4] including optimal nucleic acid and protein metabolism as well as cell growth, division, and function [5].

Interestingly, some studies have shown DM patients had increased levels of $\mathrm{Zn}$ excretion in urine compared to non-DM controls [6] and that DM patients are usually $\mathrm{Zn}$ deficient.

This has encouraged further research into the possible positive effects of $\mathrm{Zn}$ supplementation on DM patients. Several studies have shown its beneficial effects on renal pathological changes in T1D and T2D subjects by reducing oxidative stress, glomerular damage, lymphocytic infiltration, and urinary albumin excretion.

As DM incident rates increase rapidly worldwide, and the UK health service is predicted to spend 16.9 billion pounds on DM-related complications over the next 25 years, there is pressure to find treatment for this condition. Therefore, this particular study includes analysis of published findings and have found promising results that show $\mathrm{Zn}$ reducing, and in some cases completely preventing renal damage.
The intention of this paper is to highlight the significance of $\mathrm{Zn}$ and encourage further research in this area, and its potential use as a treatment against renal pathological symptoms in DM patients.

\section{Diagnosis of DM}

Blood glucose level tests are the common methods of diagnosis for DM, which include fasting glucose concentration test, poststandard carbohydrate load, and oral glucose tolerance test (OGTT). Patients with abnormally high levels of glucose in any of these tests are considered to have impaired glucose tolerance and recognised as prediabetics or diabetics.

Another diagnostic test is to measure levels of glycated haemoglobin (HbAlc), which identifies the average plasma glucose concentration over a long period of time, for a period of two to three months. High levels of HbA1c are usually seen in DM patients and individuals with renal failure. HbAlc is formed when haemoglobin binds to plasma glucose. Due to high numbers of glucose molecules binding to haemoglobin in DM patients, high levels of HbAlc is typically expected. Together with the fasting plasma glucose test, the HbAlc test is mainly used to diagnose T2D.

\section{Main Types of DM and its Mechanisms}

There are two main types of diabetes, T1D and T2D. Most patients depend on exogenous insulin for survival. Without insulin they develop severe metabolic complications such as ketoacidosis and coma. Although the clinical onset of T1D is abrupt, this disease results from chronic autoimmune attack on $\beta$-cells that usually begins several years before the disease becomes evident. The common symptoms of the disease such as hyperglycaemia and ketosis appear late in its course, after more than $90 \%$ of $\beta$-cells have been destroyed.

*Corresponding author: Zhou S, Department of Life Science, Institute of Biological and Environmental Science and Technology (iBEST), Faculty of Creative Arts, Technologies and Science, University of Bedfordshire, Park Square, Luton, LU1 3JU, United Kingdom, Tel: +00441582743541; E-mail: sbzhou@yahoo.com

Received May 22, 2015; Accepted June 08, 2015; Published June 13, 2015

Citation: Fernando J, Zhou S (2015) The Role of Zinc in Renal Pathological Changes in Diabetic Status. J Nutr Disorders Ther 5: 165. doi:10.4172/21610509.1000165

Copyright: @ 2015 Fernando J, et al. This is an open-access article distributed under the terms of the Creative Commons Attribution License, which permits unrestricted use, distribution, and reproduction in any medium, provided the original author and source are credited. 
$\mathrm{T} 2 \mathrm{D}$ is caused by a combination of peripheral resistance to insulin activity and inadequate insulin secretion by pancreatic $\beta$-cells that precedes hyperglycaemia and is typically accompanied by $\beta$-cell hyperfunction and hyperinsulinemia in early stages of DM [3].

T2D is a complex multifactorial disease where both genetic [7-9] and environmental factors [10-12] play a role. Environmental factors such as lifestyle and dietary habits, and also genetic factors are involved in the pathogenesis as evidenced by the greater concordance rate of the disease in monozygotic twins (35\% to $60 \%$ ) compared to dizygotic twins $[13,14]$.

Other types of DM fall into monogenic and secondary causes. Although the major types of DM arise by different pathogenic mechanisms, the long-term complications in kidneys, eyes, nerves, and blood vessels are the same and are the principal causes of morbidity and death. DM includes a group of metabolic disorders caused by the disruption of glucose reabsorption in kidney tubules.

\section{Glucose homeostasis and the process of filtration and reabsorption of glucose in the kidney}

In diabetic circumstances, hyperglycaemia causes filtration of large numbers of glucose molecules from blood plasma to the Bowman's capsule. High concentration of glucose in urine leads to saturation of transport proteins in the epithelium, restricting glucose molecules from leaving the kidney tubules. Urine containing high glucose solute (glycosuria) causes osmotic diuresis, increasing the volume of urine excreted out of the body (polyuria).

Normal glucose homeostasis is regulated by three interrelated processes including the production of glucose in the liver, glucose uptake and utilization by peripheral tissues, and actions of insulin and other regulatory hormones such as glucagon. Insufficient levels of insulin in the body, which occurs in DM, can cause accumulation of glucose in cells and lead to cell damage, including in renal cells.

As glomerulosclerosis progresses in DM patients with nephrotic syndrome, symptoms such as proteinuria, hypoalbuminemia, and oedema become evident. Excessive glomerulosclerosis can produce adequate levels of ischemia to the kidneys that can be seen as granular lesions on its surface [15].

\section{Zinc in the Human Body}

$\mathrm{Zn}$ is a trace element found in microorganisms, plants, and animals. Although trace quantities are contained within organisms, the presence of this transition metal has shown to be essential for biological processes [4]. Approximately 300 enzymes and more proteins contain Zn components, which emphasizes its essential role for human health. Optimal nucleic acid and protein metabolism, as well as cell growth, division, and function require sufficient availability of $\mathrm{Zn}$ [5].

In the human body, most $\mathrm{Zn}$ is found in the muscle and bone and smaller concentrations are found in some organs including the liver, gastrointestinal tract, and kidney. Oral ingestion of $\mathrm{Zn}$ leads to its absorption through the small intestine and then its release into blood serum where it can be absorbed into different areas of the body and ultimately excreted by binding to proteins such as albumin and transferrin [16].

Cellular $\mathrm{Zn}$ involves efficient homeostatic control that avoids accumulation of excess $\mathrm{Zn}$ [17] and redistributes $\mathrm{Zn}$ to avoid its deficiency in specific organs e.g. brain [18]. Cellular $\mathrm{Zn}$ homeostasis is mediated by two protein families; the Zn-importer (Zip, Zrt, Irt- like proteins) family containing 14 proteins that transport $\mathrm{Zn}$ into the cytosol, and the $\mathrm{Zn}$ transporter ( $\mathrm{ZnT}$ ) family, comprising 10 proteins transporting $\mathrm{Zn}$ out of the cytosol [19]. Regulation of homeostasis is crucial to maintain cellular viability and prevent deregulation, which can lead to damage of the cell and ultimately cell death.

Cellular $\mathrm{Zn}$ homeostasis is mediated by three main mechanisms (Figure 1). One is the transportation of $\mathrm{Zn}$ into the cytosol through the plasma membrane by importers from the Zip-family, and it is exported out of the cytosol by proteins from the ZnT-family. Another is due to $\mathrm{Zn}$-binding proteins such as metallothionein (MT) that maintain $\mathrm{Zn}$ homeostasis. To enable $\mathrm{Zn}$ re-distribution, it needs to be mobilized from its tight binding sites by coordinating $\mathrm{Zn}$ to sulphur donors. This allows direct $\mathrm{Zn}$ transfer and redox reactions to occur to the redox-inert $\mathrm{Zn}$ ion. The final main mechanism is transportermediated sequestration of $\mathrm{Zn}$ into intracellular organelles, including endoplasmic reticulum, Golgi, and lysosomes.

Intracellular $\mathrm{Zn}$ homeostasis is maintained by the MT/thioneinsystem, where free $\mathrm{Zn}$ ions bind to apo-protein thionein (Tred) to form MT (Figure 1). Elevated levels of free $\mathrm{Zn}$ ions can bind to $\mathrm{Zn}$ finger structures of the metal-regulatory transcription factor (MTF)-1, inducing the expression of Tred. Oxidation of thiols by reactive oxygen (ROS) or nitrogen (RNS) species triggers the formation of the oxidized protein thionin (Tox), which generates $\mathrm{Zn}$ signals and reduces oxidant signals, thereby reducing oxidative stress [20] (Figure 1).

MTs have been widely recognised in their involvement with $\mathrm{Zn}$

A

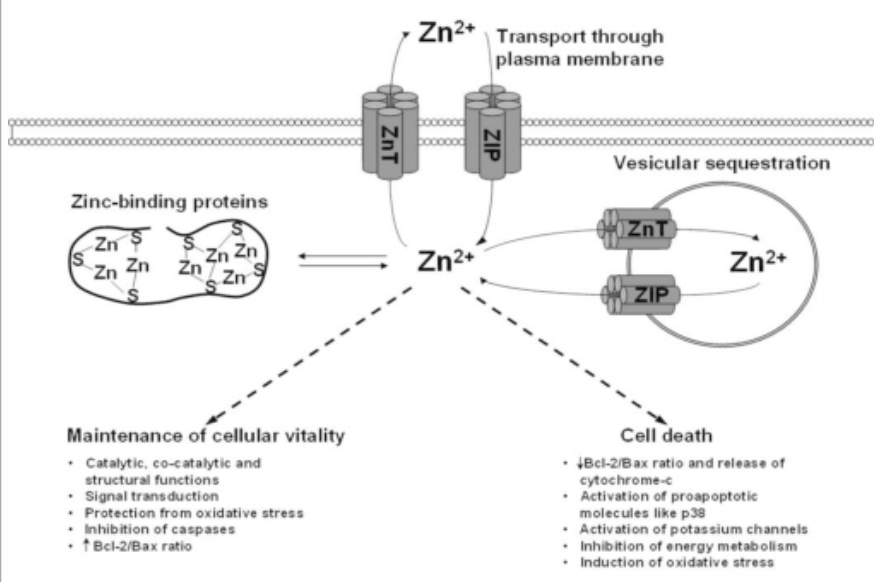

B

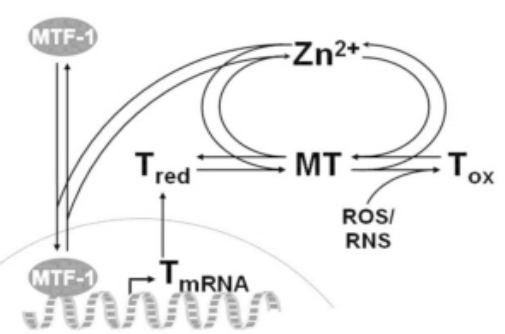

Figure 1: Cellular $\mathrm{Zn}$ homeostasis and its impact on cytotoxicity and during $\mathrm{Zn}$ deficiency. (A) Cellular $\mathrm{Zn}$ homeostasis. $\mathrm{Zn}$ is transported into the cytosol by Zip-family and exported out by ZnT-family. Zn-binding proteins (e.g. MT) maintain $\mathrm{Zn}$ homeostasis. It coordinates $\mathrm{Zn}$ to sulphur donors, allowing $\mathrm{Zn}$ transfer and redox reactions to occur. (B) Intracellular $\mathrm{Zn}$ homeostasis by the MT/thionein-system [20]. 
homeostasis. Overall, MT has a variety of functions including the regulation of apoptosis and more relevantly, the maintenance of $\mathrm{Zn}$ homeostasis. Due to the unique structural characteristics of MT, it can bind up to seven $\mathrm{Zn}$ ions. A study on the effects of MT on tubular epithelial cells in the kidney showed the up-regulation of MT stimulated the hypoxia-inducible factor and hypoxia-responsive elements (HIFHRE) pathway, which stabilizes protein expression in cells and reduces renal injury caused by hypoxia [21].

Decreased levels of $\mathrm{Zn}$ in the body can cause damaging effects towards growth, neuronal development, and immunity. There are several causes of $\mathrm{Zn}$ deficiency including insufficient dietary intake e.g. diet with lower $\mathrm{Zn}$ content, malabsorption e.g. acrodermatitis enteropathica, increased excretion e.g. chronic renal disease [22,23], and increased $\mathrm{Zn}$ loss e.g. sickle cell disease [24].

\section{Zinc and Diabetes}

In 1934, $\mathrm{Zn}$ was discovered as a component of insulin crystals therefore suggested the importance of $\mathrm{Zn}$ to maintain normal biological processes in the body. The deregulation of $\mathrm{Zn}$ homeostasis can lead to $\mathrm{Zn}$ deficiency or excess $\mathrm{Zn}$ in the body, which can affect the formation of insulin crystals that may lead to insufficient levels of insulin and result in DM.

Possible components that may be involved in $\mathrm{Zn}$ deregulation include defects in MT as this protein is predominantly involved in $\mathrm{Zn}$ homeostasis. Alternatively it could be caused by defects in the $\mathrm{Zn}$ transporter protein $\mathrm{ZnT}-8$, which delivers $\mathrm{Zn}$ ion from the cytoplasm into insulin granules [25-27].

As well as being a significant component of insulin, $\mathrm{Zn}$ also relates to DM in the sense that studies on animal DM models and human have shown increase levels of $\mathrm{Zn}$ excretion in urine compared to non-DM controls [6]. This indicates that DM patients are usually $\mathrm{Zn}$ deficient. The definite cause for this is yet unknown, however a number of studies have indicated a positive correlation between increased zincuria with polyuria, since osmotic diuresis is one of the symptoms of DM [2830]. Therefore high levels of $\mathrm{Zn}$ are excreted in urine, resulting in $\mathrm{Zn}$ deficiency in the body. Also hyperzincuria has been linked with blood glucose concentration, glycosuria and proteinuria [29,31,32].

\section{Improvements in control diabetic glycaemic level after zinc supplementation}

The relationship between $\mathrm{Zn}$ deficiency and DM has been the subject of many studies, some using animal models [33-35] and some human subjects [36,37]. Diabetic subjects are commonly tested for blood glucose levels due to inadequate levels of insulin produced by the pancreas. A study on T1D rats (by STZ administration) showed lower blood glucose levels and 24-hour urinary protein levels after 3 months of $\mathrm{Zn}$ supplication in DM subjects (Blood glucose level 15.84 $\pm 1.38 \mathrm{mmol} / \mathrm{L}, 24 \mathrm{~h}$ urine proteins $42.28 \pm 15.15 \mathrm{mg}$ ) compared to $\mathrm{DM}$ rats without $\mathrm{Zn}$ supplementation (Blood glucose level $18.03 \pm 1.72$ $\mathrm{mmol} / \mathrm{L}, 24 \mathrm{~h}$ urine proteins $59.25 \pm 11.31 \mathrm{mg}$ ) [38]. This suggested that $\mathrm{Zn}$ might be involved in preventing hyperglycaemia and proteinuria, which are common symptoms of DM-induced renal damage.

Studies have also shown the reduction of $\mathrm{HbA1c}$ in T2D patients after Zn supplementation [39-42]. A study on T2D patients suffering from microalbuminuria showed that $\mathrm{HbAlc}$ was significantly reduced from $8.0 \pm 1.4 \%$ before treatment, to $7.2 \pm 1.4 \%$ after 3 months of $\mathrm{Zn}$ supplementation [41]. Another paper studied the effects of $\mathrm{Zn}$ supplementation on $101 \mathrm{~T} 2 \mathrm{D}$ patients and the level of glycaemic control. Group 1, which included 50 patients, were given $\mathrm{Zn}$, and 51 patients in Group 2 were given a placebo. Results showed a positive correlation between serum $\mathrm{Zn}$ levels and $\mathrm{Zn}$ intake. Also after 3 months of $\mathrm{Zn}$ supplementation, $\mathrm{HbAlc} \%$ concentration decreased significantly while no significant changes were found in the control group. This indicates the beneficial effects of $\mathrm{Zn}$ supplementation in T2D as it elevated patients' serum Zn levels and improved their glycaemic control; shown by the reduction in $\mathrm{HbAlc} \%$ concentration [40]. Results from another study showed patients given $\mathrm{Zn}$ supplementation in addition to multivitamins improved glycaemic control by significantly reducing $\mathrm{HbA} 1 \mathrm{C} \%$ levels and fasting and postprandial glucose compared to patients receiving multivitamin only and placebo [42].

\section{Improvements in diabetic glomerular function after zinc supplementation}

The effects of a mixture of vitamins and minerals, including $\mathrm{Zn}$ have also shown improvements in glomerular function in T2D patients. Factors that significantly reduced are urinary albumin excretion (UAE) levels, fasting serum glucose and malondialdehyde concentrations. Malondialdehyde is a common marker for oxidative stress [43].

Several studies have investigated the effects of $\mathrm{Zn}$ supplementation on microalbuminuria in DM patients [41,44-46]. Results from studies show a significant decrease in UAE in subjects given $\mathrm{Zn}$, whereas subjects not given $\mathrm{Zn}$ exhibited consistent high UAE levels [41]. This study has shown the renal-protective effects of $\mathrm{Zn}$ by significantly reducing UAE after $\mathrm{Zn}$ supplementation, which suggests reduced permeability of renal glomerulus to albumin in patients supplied with $\mathrm{Zn}$. This also demonstrates the effectiveness of $Z n$ as these improvements were seen within only 3 months, therefore shows the potential of $\mathrm{Zn}$ to possibly prevent renal damage at a relatively fast rate. However, the limitations of this study include only measuring fasting plasma glucose and not postprandial plasma glucose concentration. Hence these levels may change after $\mathrm{Zn}$ supplementation and alter the results.

Further, another study on the effects of $\mathrm{Zn}$ on T2D patients with micro-albuminuria showed a significant decrease in homocysteine levels in the group supplemented with $30 \mathrm{mg} / \mathrm{d}$ of $\mathrm{Zn}$ for 3 months, whilst the group receiving the placebo showed no significant changes. Also high homocysteine concentrations in plasma are associated with glomerular filtration impairment [45]. Hence a decrease in this amino acid after $\mathrm{Zn}$ supplementation shows promising results.

In addition to research on damaged renal tubules, other substances involved in renal damage have been studied. For example, renal tissues from $\mathrm{Zn}$-deficient DM rats that were given $\mathrm{Zn}$ supplementation showed a reduction in levels of connective tissue growth factor (CTGF). This particular matricellular protein is critically involved in fibrosis and renal damage as it acts as a downstream mediator of transforming growth factor-beta (TGF- $\beta 1$ )-induced fibrosis [47-49]. A number of studies have shown a positive correlation between the level of renal CTGF mRNA expression and glomerulosclerosis in diabetic mice [47,48,50,51]. The effects of $\mathrm{Zn}$ supplementation on reducing CTGF levels were seen in a study that examined CTGF levels in human renal proximal tubular (HK-11) cells, which showed inhibited CTGF expression in pre-treated HK-11 cells with $\mathrm{Zn}$ compared to cells not treated with $\mathrm{Zn}$ [38]. This suggests that $\mathrm{Zn}$ supplementation had a positive effect on these renal cells by reducing the levels of this protein, which may prevent TGF- $\beta 1$ induced fibrosis and therefore reduce pathological changes in renal tissues. 


\section{Inhibition of diabetic oxidative stress after zinc supplementation}

A study on the antioxidant effects of $\mathrm{Zn}$ on $\mathrm{T} 2 \mathrm{D}$ showed initial increases in oxidative stress, which was measured according to the presence of plasma thiobarbituric acid reactive substances (TBARS), in T2D patients compared to healthy patients $(3.32+/-0.05$ micro mol/L vs. $2.08+/-0.04 \mathrm{micro} \mathrm{mol} / \mathrm{L}$ ). After six months of $\mathrm{Zn}$ supplementation, T2D patients showed a significant reduction in plasma TBARS, in contrast to the placebo group where no significant changes were seen [52]. Another similar study also showed the potential antioxidant effects of $\mathrm{Zn}$, although when combined with chromium. Plasma TBARS reduced more significantly in patients receiving $\mathrm{Zn}, \mathrm{Cr}$ or a mixture of $\mathrm{Zn}$ and $\mathrm{Cr}$ supplementation [Cr (13.6\%), $\mathrm{Zn}(13.6 \%)$ and $\mathrm{Zn} / \mathrm{Cr}(18.2 \%)$ ] [53]. However a study on T2D male patients showed $\mathrm{Zn}$ supplementation does not decrease oxidative stress in patients with normal Zn levels [54].

Hyperglycaemia has been found to be a risk factor of causing oxidative stress in DM [55]. Therefore, the relationship between hyperglycaemia and its possible effects on MT is an interesting area to focus on, since MT is involved in the counteraction of oxidative stress. As $\mathrm{Zn}$ is related to the expression of MT, the relationship between $\mathrm{Zn}$ supplementation and levels of MT expression in cells have been studied in HK-11 cells using RT-PCR methods [38]. Results showed that pretreatment of HK-11 cells with Zn induced MT expression. However, the study only used a single concentration of $\mathrm{Zn}$ (dissolved $\mathrm{ZnSO}_{4}$ in tap water) and did not examine the effects of different doses of $\mathrm{Zn}$ supplementation, which may alter MT expression. Also, the study focused on tubular cells, so the effects on other types of renal tissue may differ.

However, another study on 2 months old MT-KO (MT-I and MTII Knock Out) mice showed no significant differences in the molecular biomarkers, protein kinase B (Akt1 and Akt2), hexokinase II (HK2), and glycogen synthase kinase- 3beta (GSK-3 $\beta$ ) expression between MT-KO mice with and without Zn supplementation [56]. Results also showed that Akt1, Akt2, HK2, and GSK-3 $\beta$ expression were increased in mice with MT expression after Zn supplementation. These results show that MT is required for $\mathrm{Zn}$ treatment to be therapeutically effective for renal protection, and also MT stimulates the phosphorylation of Akt and GSK-3 and increases HK2 expression. The reason for this is unknown however researches of this study assumed that without MT there would be limited $\mathrm{Zn}$ chaperones to release $\mathrm{Zn}$ to target molecules, which is required to stimulate Akt and GSK-3 phosphorylation and HK2 expression [57].

\section{Improvements in diabetic glucose metabolism after zinc supplementation}

Akt1 and Akt2 genes are recognised for their role in the regulation of glucose uptake by mediating insulin-induced translocation of the SLC2A4/GLUT4 glucose transporter to the cell surface [58]. It also regulates cell survival by inactivating components of apoptosis machinery. GSK-3 $\beta$ is an important molecule in renal glucose metabolism as it is involved in the conversion of glucose to glycogen, and provides a preventative effect on pathogenic fibrosis of the kidney [59].

HK2 is a glycolytic enzyme that phosphorylates glucose to produce glucose-6-phosphate, the first step in most glucose metabolism pathways. Expression of the HK2 gene is insulin-responsive, and studies have shown its involvement in the increased rate of glycolysis
$[60,61]$. It is also known to regulate cytoprotection and apoptosis based on the metabolic state of the cell [62].

Studies have shown that $\mathrm{Zn}$ may play a similar role to that of insulin, causing it to stimulate Akt phosphorylation and activate glucose metabolism [63-65] and a recent study on podocytes showed the protective effects of Akt 2 against damage induced by chronic kidney disease [66]. Therefore the importance of Akt2 for glucose metabolism led to the assumption that the protective effect of $\mathrm{Zn}$ was dependent on this enzyme. However, the study on 2-month old Akt2-KO diabetic mice showed increases in Akt, p-GSK-3 $\beta$, and HK2 expression, even when the Akt2 gene was absent. Therefore implying that the deletion of Akt2 gene does not affect basal Akt phosphorylation, basal and contraction-stimulated GSK-3 $\beta$ phosphorylation, glycogen synthase phosphorylation or activity [67].

Further studies on Akt-mediated molecules have shown a link between renal pathological damage at the last stages of DM with decreased levels of Akt function in the kidneys [68-70]. A study on 3-month old T1D OVE26 mice showed abnormalities such as significantly decreased phosphorylation of Akt and GSK-3 $\beta$, decreased expression of $\mathrm{HK} 2$, and increased expression of the Akt negative regulators phosphatase and tensin homolog (PTEN), protein-tyrosine phosphatase 1B (PTP1B), and tribbles homolog 3 (TRB3) [56]. All of these were significantly prevented after $\mathrm{Zn}$ supplementation.

Inhibiting the negative regulators of Akt suggests that cells may be able to regulate glucose levels and improve intracellular conditions due to Akt availability. This may also lead to the reduction in hyperglycaemia and excess glucose in renal tissues.

\section{Improvement of diabetic renal pathology after zinc supplementation}

Most studies investigating the effects of a substance in renal tissues usually carry out histological examinations to visually detect any changes in comparison to controls [71-73]. A particular study on 3-month old T1D OVE26 mice showed after Zn supplementation, segmental glomerulosclerosis and extracellular matrix significantly decreased [56]. DM mice given saline showed excessive accumulation of extracellular matrix, which caused glomerular enlargement (Figure 2A). In addition, Sirius red staining showed excess collagen accumulation in DM mice but not in DM mice given Zn (Figure 2B). Therefore these results reveal an improvement in pathological changes after DM mice were treated with Zn (Figure 2).

Along with histological examinations, semi-quantitative analysis can provide information on the state of the renal tissues. For example, the level of fibrosis in renal tissues can be measured by semiquantitative analysis of mesangial index, tubulointerstitial damage, and GBM thickness. A study on renal cells in T1D rats showed fewer pathological changes of the glomeruli, renal tubules, and interstitium in DM subjects given $\mathrm{Zn}$ supplements compared to DM subjects given a placebo [38]. Levels of mesangial index, tubulointerstitial damage, and GBM thickness were lower in DM/Zn subjects, therefore displayed fewer renal damage (Figure 3). This suggests that $\mathrm{Zn}$ may play a protective role against cellular injury in renal tissues in addition to renal fibrosis, which is one of the pathological changes seen in DM.

\section{Protective effects of zinc supplementation on diabetic aorta oxidative damage}

As well as investigating the beneficial effects of $\mathrm{Zn}$ supplementation 


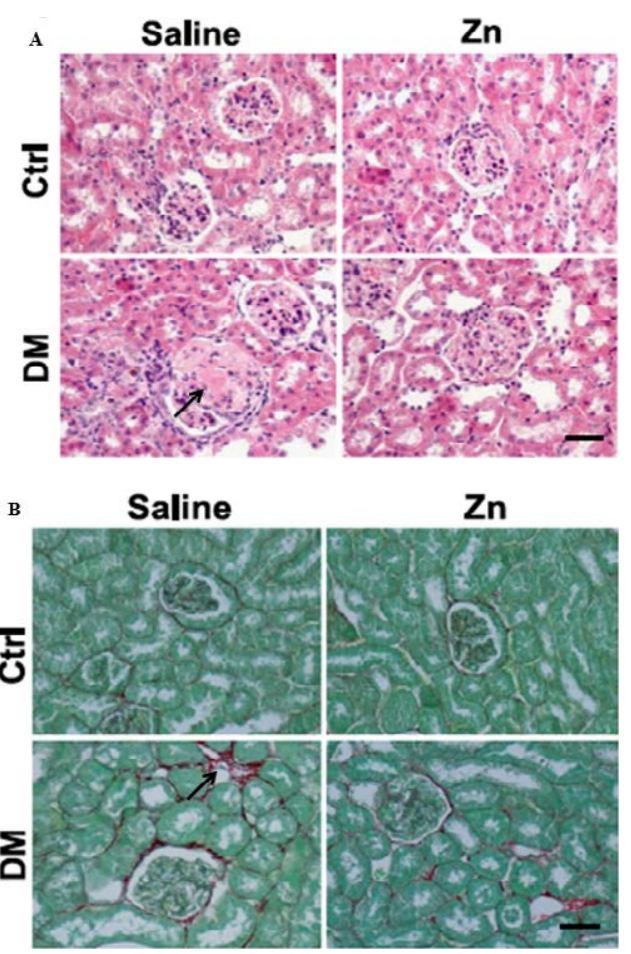

Figure 2: Histological examination of kidney tissues from 3-month old T1D OVE26 mice given saline or $\mathrm{Zn}$ supplementation. (A) Haematoxylin and eosin stain. Arrow showing accumulation of extracellular matrix, causing glomerular enlargement. (B) Sirius red stain. Arrow showing excess collagen accumulation [56].
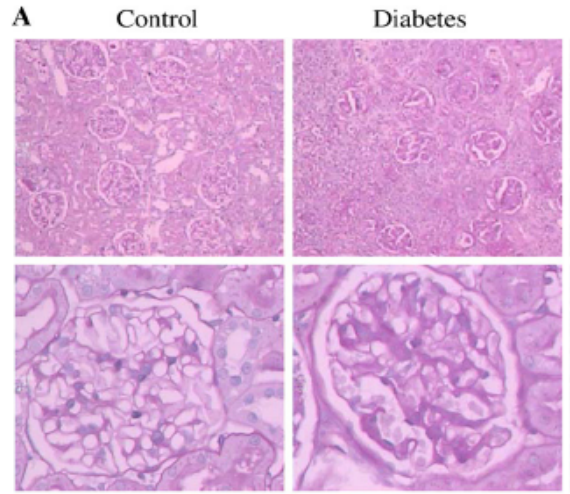

Diabetes $/ \mathrm{Zn}$

Figure 3: Semi-quantitative analysis of mesangial index, tubulointerstitial damage, and GBM thickness in T1D rats. Tissue examinations show damage in DM as thick GBM is clearly visible compared to DM/Zn tissue [38].

on renal organs, a study investigated the pathological effects of $\mathrm{Zn}$ supplementation in the aorta [74]. Results showed decreases in 4-hydroxynonenal (4-HNE) and neurotrophin-3 (3-NT) expression in tissues of T1D OVE26 mice with Zn supplementation compared to DM subjects without $\mathrm{Zn}$ supplementation. This provides important information on the state of the tissues, as these factors are involved in oxidant-induced cell signalling and apoptosis. Therefore higher quantities are usually found during oxidative stress.

The reduction in the expression of these factors as well as others (e.g. nuclear factor-like 2 transcription factor [74]) in DM subjects given $\mathrm{Zn}$ suggests that $\mathrm{Zn}$ supplementation decreases oxidative stress, and therefore reduces DM-induced oxidative damage in aortic tissue.

This provides valuable information that could be applied to renal blood vessels since renal atherosclerosis and arteriolosclerosis constitute part of the macrovascular disease seen in DM. Therefore this result may indicate that besides having beneficial effects on kidney cells, $\mathrm{Zn}$ supplementation could also have protective effects on renal blood vessels.

\section{Discussion}

In summary, a large number of studies have shown the beneficial effects of $\mathrm{Zn}$ supplementation in a range of renal components including glycaemic control, glomerular function, and oxidative stress.

When levels of insulin secretion are abnormal or sensitivity to insulin is reduced, glycaemic levels (either fasting or postprandial glucose levels) are not controlled, which develops into DM. Prolonged DM causes $\mathrm{Zn}$ homeostasis disorders, which is shown by the reduction of serum $\mathrm{Zn}$ [41]. This could be due to a restricted diet, decreased intestinal $\mathrm{Zn}$ absorption, or increased zincuria. The mechanism of renal disease complications involves the development of glycaemic disorder, oxidative stress, and pathological changes of the glomerulus (e.g. glomerulosclerosis).

This paper showed the beneficial effects of $Z n$ on various mechanisms of renal disease, including glucose transportation. This could be because increased amounts of $\mathrm{Zn}$ are transferred into pancreatic cells via increased $\mathrm{Zn}$-T8 activities that also improves glucose transporter activity (e.g. SLC2 A4/GUT4) or Akt2 that increase glucose uptake. Hence this may improve insulin activity. Also $\mathrm{Zn}$ supplementation showed improvements to glycolysis by increased activity of HK2 (in the presence of MT), a key enzyme for the conversion of glucose into glucose-6-phosphate.

A number of papers also presented reductions in oxidative stress after $\mathrm{Zn}$ supplementation, which could be caused by improvements in MT and Copper-Zn-Superoxide dismutase (SOD) activities that reduce oxidative stress biomarkers, TBARS and malondialdehyde.

Subjects that presented high CTGF levels (involved in fibrosis and renal damage) showed formation of glomerulosclerosis. However after Zn supplementation, increased GSK-3 $\beta$ activity was seen, which may have inhibited that process and reduce fibrosis.

Histological examinations displayed the decrease in collagen accumulation after $\mathrm{Zn}$ supplementation (Figure 2B) and this also reduced excessive accumulation of extracellular matrix.

Further, Zn supplementation improved 4-HNE and 3-NT factors as well as others (e.g. nuclear factor-like 2 transcription factor) in DM subjects. These factors are involved in oxidant-induced cell signalling and apoptosis. This suggests that $\mathrm{Zn}$ supplementation decreases oxidative stress, and therefore reduces DM-induced oxidative damage.

The extent to which these have improved is significant, especially when taking into account the time period of the studies. Some of the studies have shown considerable visible improvements to renal damage within three months. This could have long-term improvements for DM patients and possibly prevent end-stage renal disease, as well as reducing the number of patients needing renal dialysis and transplantation.

This study has outlined substances that have only recently been associated with DM and/or Zn, such as MT and Akt2. Further research on the effects of $\mathrm{Zn}$ on MT in renal disease may lead to future treatments 
relating $\mathrm{MT}$ and $\mathrm{Zn}$ supplementation. Likewise, additional knowledge on Akt2 and the effects of $\mathrm{Zn}$ on other Akt isoforms such as Akt1 and Akt3 would be relevant to finding treatments for DM. Therefore this needs to be studied in the future. In addition, the improvements in micro-albuminuria and levels of protein excreted in urine after $\mathrm{Zn}$ supplementation described in this study could lead to further research on the mechanism of $\mathrm{Zn}$ on reducing permeability of renal glomerulus to albumin and other proteins.

The majority of studies analysed in this paper, included research studies on animal models than human subjects. However in particular instances where human models are used, several studies showed similar beneficial effects of $\mathrm{Zn}$ as in the animal studies. Specifically, a study investigating the effects of $\mathrm{Zn}$ on micro-albuminuria in T2D patients showed a decrease in UAE as serum $\mathrm{Zn}$ increases, which is similar to that of many animal studies [41].

More research is required on $\mathrm{Zn}$ supplementation and its pathological effects on animal models to increase knowledge about suitable cellular environments needed for $\mathrm{Zn}$ to have its beneficial effects in renal tissues. This would provide vital information about the possible side effects of $\mathrm{Zn}$ supplementation and whether it is safe to use as a long-term treatment for DM patients. Further research on human subjects is crucial for this.

Studies on animal models were performed around the age of two to three months, and most of these studies show similar results to studies on human subjects over the age of 20 years, indicating that age may not be a contributing factor to the effects of $\mathrm{Zn}$ on renal pathological changes.

The effects of $\mathrm{Zn}$ supplementation on aortic damage were briefly discussed in this paper to see whether there are similarities between vascular tissues in the heart and in renal organs. Many studies showed positive effects after $\mathrm{Zn}$ supplementation. However there were also a small number not showing significant changes. For example, a study on forty males with T2D showed no significant differences with the baseline in the biomarkers F2- Isoprostanes (IsoPs) and allantoin in patients receiving $\mathrm{Zn}$ or the placebo [54]. IsoPs are involved in free radical peroxidation and have been used in a number of studies as a marker of oxidant injury in vivo [75-77]. Allantoin is a product of oxidation of uric acid by purine catabolism and has been used in clinical laboratories as a determination of oxidative stress in humans. Therefore unchanged levels of allantoin and IsoPs suggest $\mathrm{Zn}$ supplementation had no beneficial effects on oxidative stress.

Many previous studies have shown the positive effects of $\mathrm{Zn}$, so this study provides important information that $\mathrm{Zn}$ supplementation may not have beneficial effects in certain situations. However, this study did not measure levels of $\mathrm{Zn}$ co-transporters in addition to $\mathrm{Zn}$ levels, and these are important factors to consider, as they are involved in the regulation of $\beta$-cell insulin processing and excretion. Therefore, variations in levels of co-transporters may have prevented $\mathrm{Zn}$ from having any effects. In addition, DM patients with low $\mathrm{Zn}$ levels were not used in this study and only males were included. Zn supplementation may have different effects on diabetic females with suboptimal or optimal Zn levels, which is frequently seen in DM patients. Also, the duration of this study was only 4 months so increasing the length of this study might produce different results.

\section{Conclusion}

To conclude, all research articles mentioned in this study provides vital information about the relationship between $\mathrm{Zn}$ and DM because
Zn deficiency is commonly seen in DM patients as a result of elevated urinary $\mathrm{Zn}$ excretion, decreased intestinal $\mathrm{Zn}$ absorption, and restricted diet. Therefore these findings emphasize the importance of regularly monitoring $\mathrm{Zn}$ levels in diabetic patients. The majority of studies aforementioned have demonstrated the beneficial effects of $\mathrm{Zn}$ supplementation on renal pathology of both T1D and T2D subjects. Despite this, there are some studies that have had limited impact on renal tissues after the administration of $\mathrm{Zn}$. Therefore, the aim of this paper is to encourage further research in this area to consider $\mathrm{Zn}$ as a potential treatment against long-term renal damage in diabetic patients, which would decrease DM mortality rates due to renal damage, and reduce costs by national health services.

\section{Acknowledgement}

This work was supported by the Rising Star Research Investment fund by University of Bedfordshire.

\section{References}

1. Zimmet PZ, Magliano DJ, Herman WH, Shaw JE (2014) Diabetes: A 21st century challenge. Lancet Diabetes Endocrinol 2: 56-64.

2. American Diabetes Association (2009) Diagnosis and Classification of Diabetes Mellitus. Diabetes Care 32(Suppl 1): S62-S67.

3. Abbas AK, Aster JC, Kumar V (2013) Diabetes mellitus: Robbins basic pathology. (9thedn), PA: Saunders. Philadelphia 739.

4. Kelleher SL, McCormick NH, Velasquez V, Lopez V (2011) Zinc in specialized secretory tissues: Roles in the pancreas, prostate, and mammary gland. Adv Nutr 2: 101-111.

5. Vallee BL and Falchuk KH (1993) The biochemical basis of zinc physiology. Physiol Rev 73: 79-118.

6. Maldonado Martin A, Gil Extremera B, Fernandez Soto M, Ruiz Martinez M Gonzalez Jimenez A, et al. (1991) Zinc levels after intravenous administration of zinc sulphate in insulin-dependent diabetes mellitus patients. Klin Wochenschr 69: $640-644$

7. Hara K, Boutin P, Mori Y, Tobe K, Dina C, et al. (2002) Genetic variation in the gene encoding adiponectin is associated with an increased risk of type 2 diabetes in the japanese population. Diabetes 51: 536-540.

8. Grant SF, Thorleifsson G, Reynisdottir I, Benediktsson R, Manolescu A, et al. (2006) Variant of transcription factor 7-like 2 (TCF7L2) gene confers risk of type 2 diabetes. Nat Genet 38: 320-323.

9. Horikawa Y, Oda N, Cox NJ, Li X, Orho-Melander M, et al. (2000) Genetic variation in the gene encoding calpain-10 is associated with type 2 diabetes mellitus. Nat Genet 26: 163-75.

10. Sobngwi E, Boudou P, Mauvais-Jarvis F, Leblanc H, Velho G, et al. (2003) Effect of a diabetic environment in utero on predisposition to type 2 diabetes. Lancet 361: 1861-1865.

11. Tuomilehto J, Lindstrom J, Eriksson JG, Valle TT, Hamalainen H, et al. (2001) Prevention of type 2 diabetes mellitus by changes in lifestyle among subjects with impaired glucose tolerance. N Engl J Med 344: 1343-1350.

12. Kahn SE, Hull RL, Utzschneider KM. (2006) Mechanisms linking obesity to insulin resistance and type 2 diabetes. Nature 444: 840-846.

13. Barnett AH, Eff C, Leslie RD, Pyke DA (1981) Diabetes in identical twins. A study of 200 pairs. Diabetologia 20: $87-93$

14. Newman B, Selby JV, King MC, Slemenda C, Fabsitz R, et al. (1987) Concordance for type 2 (non-insulin-dependent) diabetes mellitus in male twins. Diabetologia 30: 763-768.

15. Bonsib SM (2013) Renal vascular diseases: Atlas of medical renal pathology Springer. New York. 147

16. Valko M, Morris H, Cronin MT (2005) Metals, toxicity and oxidative stress. Curr Med Chem 12: 1161-1208.

17. Fukada T, Yamasaki S, Nishida K, Murakami M, Hirano T (2011) Zinc homeostasis and signaling in health and diseases: Zinc signaling. Journal of Biological Inorganic Chemistry 16: 1123-1134.

18. Takeda A, Minami A, Takefuta S, Tochigi M, Oku N (2001) Zinc homeostasis in the brain of adult rats fed zinc-deficient diet. J Neurosci Res 63: 447-452. 
19. Lichten LA and Cousins RJ (2009) Mammalian zinc transporters: Nutritional and physiologic regulation. Annu Rev Nutr 29: 153-176.

20. Plum LM, Rink L, Haase H (2010) The essential toxin: Impact of zinc on human health. Int J Environ Res Public Health 7: 1342-1365

21. Kojima I, Tanaka T, Inagi R, Nishi H, Aburatani H, et al. (2009) Metallothionein is upregulated by hypoxia and stabilizes hypoxia-inducible factor in the kidney. Kidney Int 75: 268-277.

22. Wang K, Zhou B, Kuo YM, Zemansky J, Gitschier J (2002) A novel member of a zinc transporter family is defective in acrodermatitis enteropathica. Am J Hum Genet 71: 66-73

23. Frustaci A, Sabbioni E, Fortaner S, Farina M, del Torchio R, et al. (2012) Selenium- and zinc-deficient cardiomyopathy in human intestinal malabsorption Preliminary results of selenium/zinc infusion. Eur J Heart Fail 14: 202-210.

24. Prasad AS, Beck FW, Kaplan J, Chandrasekar PH, Ortega J, et al. (1999) Effect of zinc supplementation on incidence of infections and hospital admissions in sickle cell disease (SCD). Am J Hematol 61: 194-202.

25. Chimienti F, Devergnas S, Favier A, Seve M (2004) Identification and cloning of a beta-cell-specific zinc transporter, $\mathrm{ZnT}-8$, localized into insulin secretory granules. Diabetes 53: 2330-2337.

26. Chimienti F, Devergnas S, Pattou F, Schuit F, Garcia-Cuenca R, et al. (2006) In vivo expression and functional characterization of the zinc transporter ZnT8 in glucose-induced insulin secretion. J Cell Sci 119: 4199-4206.

27. Wenzlau JM, Juhl K, Yu L, Moua O, Sarkar SA, et al. (2007) The cation efflux transporter ZnT8 (Slc30A8) is a major autoantigen in human type 1 diabetes. Proc Natl Acad Sci U S A 104: 17040-17045.

28. Awadallah R, El-Dessoukey EA, Doss H, Khalifa K, el-Hawary Z (1978) Bloodreduced glutathione, serum ceruloplasmin and mineral changes in juvenile diabetes. Z Ernahrungswiss 17: 79-83.

29. Canfield WK, Hambidge KM, Johnson LK (1984) Zinc nutriture in type diabetes mellitus: Relationship to growth measures and metabolic control. J Pediatr Gastroenterol Nutr 3: 577-584.

30. Lau AL, Failla ML. (1984) Urinary excretion of zinc, copper and iron in the streptozotocin-diabetic rat. J Nutr 114: 224-233.

31. McNair P, Kiilerich S, Christiansen C, Christensen MS, Madsbad S, et al. (1981) Hyperzincuria in insulin treated diabetes mellitus--its relation to glucose homeostasis and insulin administration. Clin Chim Acta 112: 343-348.

32. Quilliot D, Dousset B, Guerci B, Dubois F, Drouin P, et al. (2001) Evidence that diabetes mellitus favors impaired metabolism of zinc, copper, and selenium in chronic pancreatitis. Pancreas 22: 299-306.

33. Zhang C, Lu X, Tan Y, Li B, Miao X, et al. (2012). Diabetes-Induced Hepatic Pathogenic Damage, Inflammation, Oxidative Stress, and Insulin Resistance Was Exacerbated in Zinc Deficient Mouse Model. PLoS ONE 7: e49257.

34. Langoni Cassettari L, Colli Rocha Dias P, Natália Lucchesi A, Ferraz de Arruda M, Veruska Paiva Ortolan, É, et al. (2014) Continuous Electrical Current and Zinc Sulphate Administered by Transdermal Iontophoresis Improves Skin Healing in Diabetic Rats Induced by Alloxan: Morphological and Ultrastructura Analysis. Journal of Diabetes Research 2014: 980232.

35. Zhao Y, Wu J, Zhu H, Song P, Zou MH. (2013) Peroxynitrite-Dependent Zinc Release and Inactivation of Guanosine 5'-Triphosphate Cyclohydrolase 1 Instigate Its Ubiquitination in Diabetes. Diabetes 62: 4247-4256.

36. Giacconi R, Simm A, Santos AN, Costarelli L, Malavolta M, et al. (2014) Influence of $+1245 \mathrm{~A} / \mathrm{G}$ MT1A polymorphism on advanced glycation endproducts (AGEs) in elderly: effect of zinc supplementation. Genes \& Nutrition 9: 426

37. Pinna A, Masala S, Blasetti F, Maiore I, Cossu D, et al. (2014) Detection of Serum Antibodies Cross-Reacting with Mycobacterium avium Subspecies paratuberculosis and Beta-Cell Antigen Zinc Transporter 8 Homologous Peptides in Patients with High-Risk Proliferative Diabetic Retinopathy. PLoS ONE 9: e107802.

38. Tang Y, Yang Q, Lu J, Zhang X, Suen D, et al. (2010) Zinc supplementation partially prevents renal pathological changes in diabetic rats. J Nutr Biochem 21: $237-246$

39. Afkhami-Ardekani M, Karimi M, Mohammadi SM, Nourani F, Soheilykhah S (2009) Comparison of the effects of sodium metavanadate and zinc sulfate supplementation on lipid and glucose in patients with type 2 diabetes. ljdo 1 : 22-9.

40. Al-Maroof RA, Al-Sharbatti SS. (2006) Serum zinc levels in diabetic patients and effect of zinc supplementation on glycemic control of type 2 diabetics. Saudi Med J 27: 344-350.

41. Parham M, Amini M, Aminorroaya A, Heidarian E (2008) Effect of zinc supplementation on microalbuminuria in patients with type 2 diabetes: A double blind, randomized, placebo-controlled, cross-over trial. Rev Diabet Stud 5: 102 109.

42. Gunasekara P, Hettiarachchi M, Lekamwasam S, Liyanage C (2011) Blood sugar lowering effect of zinc and multi vitamin/mineral supplementation is dependent on initial fasting blood glucose. J Diabetol 1: 2.

43. Farvid MS, Jalali M, Siassi F, Hosseini M (2005) Comparison of the effects of vitamins and/or mineral supplementation on glomerular and tubular dysfunction in type 2 diabetes. Diabetes Care 28: 2458-2464.

44. Abdelhafez AM, El-Ashmony SMA, Morsi HK (2012) Effect of zinc supplementation on glycemic control, lipid profile, and renal functions in patients with type II diabetes: A single blinded, randomized, placebo-controlled, trial. J Biol Agric Health Care 2: 33-41.

45. Heidarian E, Amini M, Parham M, Aminorroaya A (2009) Effect of zinc supplementation on serum homocysteine in type 2 diabetic patients with microalbuminuria. Rev Diabet Stud 6: 64-70.

46. Khan MI, Siddique KU, Ashfaq F, Ali W, Reddy HD, et al. (2013) Effect of highdose zinc supplementation with oral hypoglycemic agents on glycemic contro and inflammation in type-2 diabetic nephropathy patients. J Nat Sci Biol Med 4: 336-340.

47. Riser BL, Denichilo M, Cortes P, Baker C, Grondin JM, et al. (2000) Regulation of connective tissue growth factor activity in cultured rat mesangial cells and its expression in experimental diabetic glomerulosclerosis. J Am Soc Nephrol 11: $25-38$

48. Twigg SM, Joly AH, Chen MM, Tsubaki J, Kim HS, et al. (2002) Connective tissue growth factor/IGF-binding protein-related protein-2 is a mediator in the induction of fibronectin by advanced glycosylation end-products in human dermal fibroblasts. Endocrinology 143:1260-1269.

49. Lam S, van der Geest RN, Verhagen NA, van Nieuwenhoven FA, Blom IE, et al. (2003) Connective tissue growth factor and igf-I are produced by human renal fibroblasts and cooperate in the induction of collagen production by high glucose. Diabetes 52: 2975-2983.

50. Twigg SM, Cao Z, MCLennan SV, Burns WC, Brammar G, et al. (2002) Rena connective tissue growth factor induction in experimental diabetes is prevented by aminoguanidine. Endocrinology 143: 4907-4915.

51. Liu BC, Chen Q, Luo DD, Sun J, Phillips AO, et al. (2003) Mechanisms of irbesartan in prevention of renal lesion in streptozotocin-induced diabetic rats. Acta Pharmacol Sin 24: 67-73.

52. Roussel AM, Kerkeni A, Zouari N, Mahjoub S, Matheau JM, et al. (2003) Antioxidant effects of zinc supplementation in tunisians with type 2 diabetes mellitus. J Am Coll Nutr 22: 316-321.

53. Anderson RA, Roussel AM, Zouari N, Mahjoub S, Matheau JM, et al. (2001) Potential antioxidant effects of zinc and chromium supplementation in people with type 2 diabetes mellitus. J Am Coll Nutr 20: 212-218.

54. Seet RC, Lee CY, Lim EC, Quek AM, Huang H, et al. (2011) Oral zinc supplementation does not improve oxidative stress or vascular function in patients with type 2 diabetes with normal zinc levels. Atherosclerosis 219: 231 239

55. Fiorentino TV, Prioletta A, Zuo P, Folli F (2013) Hyperglycemia-induced oxidative stress and its role in diabetes mellitus related cardiovascular diseases. Curr Pharm Des 19: 5695-5703.

56. Sun W, Wang Y, Miao X, Wang Y, Zhang L, et al. (2014) Renal improvement by zinc in diabetic mice is associated with glucose metabolism signaling mediated by metallothionein and akt, but not Akt2. Free Radic Biol Med 68: 22-34.

57. Costello LC, Guan Z, Franklin RB, Feng P (2004) Metallothionein can function as a chaperone for zinc uptake transport into prostate and liver mitochondria. $J$ Inorg Biochem 98: 664-666.

58. Yang J, Li S, Liu Y (2013) Systematic analysis of diabetes- and glucose metabolism-related proteins and its application to Alzheimer's disease. Journal of Biomedical Science and Engineering 6: 615-644. 
Citation: Fernando J, Zhou S (2015) The Role of Zinc in Renal Pathological Changes in Diabetic Status. J Nutr Disorders Ther 5: 165. doi:10.4172/21610509.1000165

59. Gong R, Ge Y, Chen S, Liang E, Esparza A, et al. (2008) Glycogen synthase kinase 3beta: A novel marker and modulator of inflammatory injury in chronic renal allograft disease. Am J Transplant 8: 1852-1863.

60. Wolf A, Agnihotri S, Micallef J, Mukherjee J, Sabha N, et al. (2011) Hexokinase 2 is a key mediator of aerobic glycolysis and promotes tumor growth in human glioblastoma multiforme. J Exp Med 208: 313-326.

61. Fang R, Xiao T, Fang Z, Sun Y, Li F, et al. (2012) MicroRNA-143 (miR-143) Regulates Cancer Glycolysis via Targeting Hexokinase 2 Gene. The Journal of Biological Chemistry 287: 23227-23235.

62. Yuan S, Fu Y, Wang X, Shi H, Huang Y, et al. (2008) Voltage-dependent anion channel 1 is involved in endostatin-induced endothelial cell apoptosis. Faseb J 22: 2809-2820.

63. Georgiades SN, Mak LH, Angurell I, Rosivatz E, Firouz Mohd Mustapa M, et al (2011) Identification of a potent activator of akt phosphorylation from a novel series of phenolic, picolinic, pyridino, and hydroxamic zinc(II) complexes. J Biol Inorg Chem 16: 195-208.

64. Ilouz R, Kaidanovich O, Gurwitz D, Eldar-Finkelman $\mathrm{H}$ (2002) Inhibition of glycogen synthase kinase-3beta by bivalent zinc ions: Insight into the insulinmimetic action of zinc. Biochem Biophys Res Commun 295: 102-106.

65. Tang X, Shay NF (2001) Zinc has an insulin-like effect on glucose transport mediated by phosphoinositol-3-kinase and akt in 3T3-L1 fibroblasts and adipocytes. J Nutr 131: 1414-1420.

66. Canaud G, Bienaime F, Viau A, Treins C, Baron W, et al. (2013) AKT2 is essential to maintain podocyte viability and function during chronic kidney disease. Nat Med 19: 1288-1296.

67. Sakamoto K, Arnolds DE, Fujii N, Kramer HF, Hirshman MF, et al. (2006) Role of Akt2 in contraction-stimulated cell signaling and glucose uptake in skeletal muscle. Am J Physiol Endocrinol Metab 291: E1031-E1037.

68. Mason S, Hader C, Marlier A, Moeckel G, Cantley LG (2014) Met activation is required for early cytoprotection after ischemic kidney injury. J Am Soc Nephrol 25: 329-337

69. Kawakami T, Ren S, Duffield JS (2013) Wnt signalling in kidney diseases: Dual roles in renal injury and repair. J Pathol 229: 221-231.

70. 70. Zhou D, Tan RJ, Lin L, Zhou L, Liu Y (2013) Activation of hepatocyte growth factor receptor, c-met, in renal tubules is required for renoprotection after acute kidney injury. Kidney Int 84: 509-520.

71. Alkaladi A, Abdelazim AM, Afifi M (2014) Antidiabetic activity of zinc oxide and silver nanoparticles on streptozotocin-induced diabetic rats. Int J Mol Sci 15 2015-2023.

72. Nicolson TJ, Bellomo EA, Wijesekara N, Loder MK, Baldwin JM, et al. (2009) Insulin storage and glucose homeostasis in mice null for the granule zinc transporter $\mathrm{ZnT} 8$ and studies of the type 2 diabetes-associated variants. Diabetes 58: 2070-2083.

73. Ho E, Quan N, Tsai YH, Lai W, Bray TM (2001) Dietary zinc supplementation inhibits NFkappaB activation and protects against chemically induced diabetes in CD1 mice. Exp Biol Med (Maywood) 226: 103-11.

74. Miao X, Wang $Y$, Sun J, Sun W, Tan $Y$, et al. (2013). Zinc protects against diabetes-induced pathogenic changes in the aorta: roles of metallothionein and nuclear factor (erythroid-derived 2)-like 2. Cardiovascular Diabetology 12: 54.

75. Michoulas A, Tong V, Teng XW, Chang TK, Abbott FS, et al. (2006) Oxidative stress in children receiving valproic acid. J Pediatr 149: 692-696.

76. Lim PS, Chang YM, Thien LM, Wang NP, Yang CC, et al. (2002) 8-isoprostaglandin F2alpha as a useful clinical biomarker of oxidative stress in ESRD patients. Blood Purif 20: 537-542.

77. Park K, Gross M, Lee DH, Holvoet P, Himes JH, et al. (2009) Oxidative stress and insulin resistance: The coronary artery risk development in young adults study. Diabetes Care 32: 1302-1307.
Citation: Fernando J, Zhou S (2015) The Role of Zinc in Renal Pathological Changes in Diabetic Status. J Nutr Disorders Ther 5: 165. doi:10.4172/2161 0509.1000165
Submit your next manuscript and get advantages of OMICS Group submissions

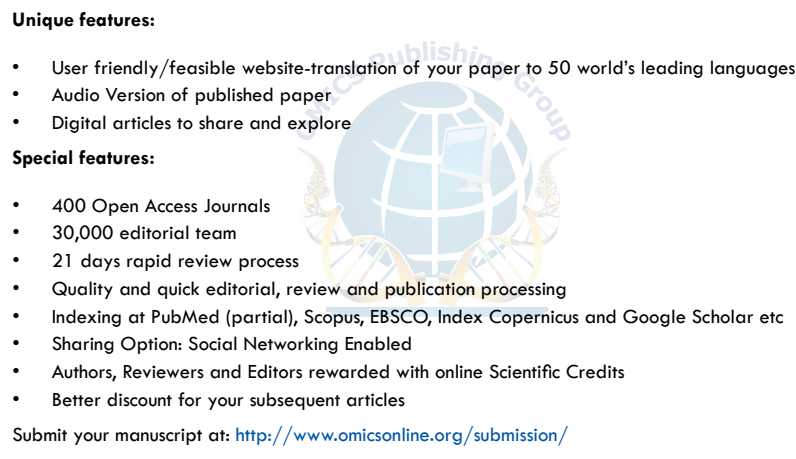

